\title{
Pre-emptive multimodal analgesia with tramadol and ketamine-lidocaine infusion for suppression of central sensitization in a dog model of ovariohysterectomy
}

This article was published in the following Dove Press journal:

Journal of Pain Research

\author{
Ubedullah Kaka ${ }^{1,2}$ \\ Nor-Alimah Rahman' \\ Adamu Abdul Abubakar ${ }^{1,3}$ \\ Yong Meng Goh ${ }^{2,4}$ \\ Sharida Fakurazi ${ }^{5,6}$ \\ Mohamed Ariff Omar ${ }^{4}$ \\ Hui Cheng Chen' \\ 'Department of Companion Animal \\ Medicine and Surgery, Faculty of \\ Veterinary Medicine, ${ }^{2}$ Institute of \\ Tropical Agriculture and Food \\ Security, Universiti Putra Malaysia, \\ Serdang, Malaysia; ${ }^{3}$ Department of \\ Veterinary Surgery and Radiology, \\ Usmanu Danfodiyo University, Sokoto, \\ Nigeria; ${ }^{4}$ Department of Preclinical \\ Veterinary Sciences, Faculty of \\ Veterinary Medicine, ${ }^{5}$ Laboratory of \\ Vaccines and Immunotherapeutics, \\ Institute of Bioscience, ${ }^{6}$ Department \\ of Human Anatomy, Faculty of \\ Medicine and Health Science, \\ Universiti Putra Malaysia, Serdang, \\ Malaysia
}

Objectives: The effects of pre-emptive infusion of ketamine-lidocaine with tramadol on the suppression of central sensitization were investigated in a dog ovariohysterectomy model.

Patients and methods: Twelve dogs were randomly assigned to two groups: ketaminelidocaine-tramadol (KLT) and tramadol (T) groups. Both groups received intravenous tramadol $4 \mathrm{mg} / \mathrm{kg}$ body weight as premedication. Immediately after induction, the KLT group received ketamine and lidocaine at 0.5 and $2 \mathrm{mg} / \mathrm{kg}$ loading dose, followed by continuous rate infusion of 50 and $100 \mu \mathrm{g} / \mathrm{kg} / \mathrm{min}$, respectively, for 2 hours. Dogs in T group received saline bolus and continuous rate infusion at equi-volume. Intraoperatively, hemodynamic responses to surgical stimulation were recorded, whereas postoperative pain was evaluated using an algometer and short form of the Glasgow composite measure pain scale.

Results: Intraoperatively, hemodynamic responses to surgical stimulation were obtunded to a greater degree in KLT compared to T group. Postoperatively, the pain scores increased only for the first hour in KLT group, compared to 12 hours in T group. Mechanical thresholds at the abdomen decreased postoperatively between 12 and 60 hours in KLT group versus the entire 72 hours in T group. Thresholds at tibia and radius in both groups increased in the immediate 1 hour postoperatively, but decreased thereafter. Significant decrement of thresholds from baseline were detected in the tibia at 24, 42 , and 60 hours in KLT group compared to 24-72 hours in T group, and in the radius between 36 and 48 hours in T group, but none in KLT group. Conclusion: Addition of pre-emptive ketamine-lidocaine infusion to single intravenous dose of tramadol enhanced attenuation of central sensitization and improved intra- and postoperative analgesia.

Keywords: pre-emptive multimodal analgesia, ketamine, lidocaine, tramadol, central sensitization, postoperative pain

\section{Introduction}

International Association for the Study of Pain has designated 2017 as the global year against pain after surgery. Surgery can alter the neuroplasticity of spinal cord, leading to the development of central sensitization. ${ }^{1,2}$ Long-term potentiation (LTP), a longlasting increase of synaptic strength at the C-fiber synapses, ${ }^{3-5}$ as well as stimulation of glial cells and dorsal root ganglion cell body cross-talk ${ }^{6}$ in the spinal dorsal horn has also been proposed as the potential mechanism to play a role in central sensitization; this would lead to enhanced pain perception in the postoperative period, clinically manifested as allodynia, secondary hyperalgesia, and dysthesias. Therefore, strategies
Correspondence: Hui Cheng Chen Department of Companion Animal Medicine and Surgery, Faculty of Veterinary Medicine, Universiti Putra Malaysia, 43400 Serdang, Selangor, Malaysia

Tel +60386093911

Fax +6038947 | 97 |

Email chen@upm.edu.my 
that could reduce central sensitization would help to manage postoperative pain effectively.

Sodium channels, opioid receptors, and $N$-methyl-Daspartate (NMDA) receptors play a crucial role in the LTP and the central sensitization. ${ }^{7-11}$ Sodium channels play a role in the transmission of nociceptive inputs through $\mathrm{C}$-fibers from the site of surgery to the dorsal horn of the spinal cord. Opioid receptors play a role in the modulation, and among other main triggers, NMDA receptors are principally the most responsible for the plasticity of central nervous system. ${ }^{12-14}$ Employment of a multimodal strategy that combines drugs from different classes of analgesics may achieve better control of acute postsurgical pain, while allowing for opioid-sparing effect. ${ }^{15}$ Combination of ketamine, acting on glutamateactivated NMDA receptors, ${ }^{8,16}$ lidocaine, acting on sodium channels,,${ }^{17,18}$ and tramadol, a centrally acting analgesic with dual action acting on $\mu \mathrm{l}$ opioid receptor and the monoaminergic pathway, responsible for noradrenaline and serotonin (5-hydroxytryptamine [5-HT]) reuptake, ${ }^{19,20}$ may prevent development of central sensitization with less pain in the postoperative period. Combination of lidocaine and ketamine as a nonopioid adjunct can enhance the efficacy, ${ }^{21}$ decrease the drug-related side effects, ${ }^{22}$ and reduce the opioid requirement and their side effects in the postoperative period. ${ }^{23}$

In humans and animals, pre-emptive ${ }^{24-31}$ and multimoda ${ }^{32-34}$ analgesia has been reported to control pain more effectively than administering analgesics postoperatively or alone. Successful pre-emptive multimodal analgesia may increase the nociceptive threshold and minimize or block nociceptor activation..$^{35}$

Perioperative infusions of ketamine or lidocaine for analgesia have been used on humans ${ }^{36-38}$ and animals ${ }^{33,39-41}$ with varying degree of success reported. McCarthy et $\mathrm{al}^{37}$ reported clear advantage of systemic lidocaine in abdominal surgery in humans (including reduced pain score, reduced postoperative analgesic requirement, and decreased intraoperative anesthetic requirements, as well as faster return of bowel function and decreased length of hospital stay). The difference may be related to the different infusion regimens, surgical procedures, and severity of pain. We recently described a higher loading dose and infusion rates that increased the mechanical thresholds in conscious dogs. ${ }^{42}$ Combination of ketaminelidocaine infusion with tramadol for their effects on central sensitization and pain has not been reported yet. Therefore, we tested if short-term infusion of ketamine-lidocaine for 2 hours confers additional analgesia to that of tramadol in a dog model of ovariohysterectomy. Tramadol, a centrally acting analgesic with dual mechanism of action, was chosen as it is widely available in most developing countries and has negligible respiratory, cardiovascular, and gastrointestinal effects than other typical opioids. ${ }^{43}$

\section{Materials and methods}

\section{Animals}

The study was conducted as approved by the Universiti Putra Malaysia Animal Care and Use Committee (UPM/IACUC/ AUP-R023/2013) and conformed to the Malaysian Code of Practice in the Care and Use of Animals for Scientific Purposes. Twelve healthy adult female dogs of mixed breed with a mean body weight of $15.42 \pm 2.83 \mathrm{~kg}$ and $2-10$ years of age underwent ovariohysterectomy. Dogs were divided into two groups of six dogs each: ketamine-lidocaine-tramadol (KLT) and tramadol alone (T) groups. Dogs were judged healthy based on the physical examination, hematology, and blood biochemistry parameters. Housing consisted of one dog per kennel with the dimension of $2.6 \times 5.6$ feet, with tiled floor. Animals were fed with commercial dog feed twice daily with water ad libitum.

\section{Anesthesia and surgical protocol}

Dogs were fasted for 12 hours before anesthesia with free access to water. Right forelimbs of the animals were shaved with a clipper and aseptically catheterized with a 20 -gauge catheter placed in cephalic veins (Vasofix ${ }^{\circledR}$ Braunule ${ }^{\circledR}$; B Braune Melsungen AG, Melsungen, Germany) for infusion of the treatment. Anesthesia was induced by administration of propofol $(5 \mathrm{mg} / \mathrm{kg}$ intravenous [IV], Profol ${ }^{\mathrm{TM}} 1 \%$; Claris Lifesciences Limited, Ahmedabad, India) over $1 \mathrm{~min}$, intubated, and maintained with isoflurane (Isoflurane USP; Piramal Health Care, Andhra Pradesh, India) in oxygen; all the animals breathed spontaneously. During surgery, vaporizer was adjusted to maintain the end-tidal isoflurane concentration (ETiso) at $1.4 \%$. If the dog moved, surgical manipulation was halted and anesthesia deepened. Surgery resumed once the dog was judged to be in surgical plane, and vaporizer was reset to previous setting.

Dogs were then placed in lateral recumbency. Lactated Ringer's solution (B Braun Medical Industries, Penang, Malaysia) was administered at the rate of $10 \mathrm{~mL} / \mathrm{kg} / \mathrm{hour}$ throughout the surgery. Noninvasive systolic, mean, and diastolic blood pressure, electrocardiogram, pulse oximetry, esophageal temperature, and airway gases were measured using a multiparametric monitor (GE Healthcare, Helsinki, Finland). A blood pressure cuff of $40 \%-60 \%$ circumference of the antebrachium was used to measure blood pressure. Ovariohysterectomy was performed via midline approach using the three-clamp pedicle technique. The abdominal 
wall was closed using $2 / 0$ Vicryl, with simple continuous pattern on the linea alba, modified Cushing on the subcutaneous layer, and intradermal on the skin. All surgeries were performed by a single experienced surgeon.

\section{Treatment groups}

Dogs were randomly assigned to two groups of six dogs each: KLT and T groups. Both groups received IV tramadol (ANALAB 50 mg; Biolab Co. Ltd, Praksa Samut Prakan, Thailand) $4 \mathrm{mg} / \mathrm{kg}$ as premedication. Immediately after induction, the KLT group received ketamine (Narketan ${ }^{\circledR}-10,100 \mathrm{mg}$ / $\mathrm{mL}$; Vetoquinol UK Limited, Buckingham, UK) and lidocaine (Xylocaine $^{\circledR} 2 \%$ [20 mg/mL]; AstraZeneca, Courbevoie, France) at 0.5 and $2 \mathrm{mg} / \mathrm{kg}$ loading dose, followed by continuous rate infusion (CRI) of 50 and $100 \mu \mathrm{g} / \mathrm{kg} / \mathrm{min}$, respectively. Dogs in T group received saline bolus and CRI at equi-volume. Following skin preparation and transfer to the operating theater, skin incision typically started 30 min after the start of treatment infusion and anesthesia induction. Ketamine-lidocaine or saline was infused for a total duration of 2 hours, covering the periods before skin incision, throughout the surgery, and during recovery, until the 2-hour duration of infusion had ended. The ketamine-lidocaine combination was prepared by diluting 0.6 $\mathrm{mL}$ of Narketan-10 into $5.4 \mathrm{~mL}$ saline and was mixed with $6 \mathrm{~mL}$ of Xylocaine $2 \%$. The mixture was infused at $0.6 \mathrm{~mL} /$ $\mathrm{kg}$ /hour using a syringe pump (Omnifuse; Graseby Medical Limited, Coulsdon, UK). The doses of ketamine and lidocaine were selected on the basis of a previous study. ${ }^{42}$

\section{Intraoperative physiological and anesthetic parameters}

Intraoperative heart rate, blood pressure, respiration rate, body temperature, and airway gases were recorded during skin preparation as baseline and throughout surgery, at skin incision, pulling of first and second pedicles, clamping of uterine body, and suturing of linea alba, subcutaneous layer, and skin.

\section{Assessment of sedation and postoperative pain}

All assessments were performed by two observers blinded to the treatment. Sedation score was recorded on a scale based on Savvas et al at 0 hour at any time before surgery and 1, 2, 4, 6, and 8 hours after extubation. ${ }^{44}$ Short form of the Glasgow composite measure pain scale (CMPS-SF) was used to assess pain subjectively. Pain was assessed before surgery as baseline at 0 hour and after extubation at 1, 2, 4, $6,8,12,18,24,30,36,42,48,60$, and 72 hours. Provision of rescue analgesia was planned with tramadol $4 \mathrm{mg} / \mathrm{kg} \mathrm{IV}$, if the CMPS-SF pain score exceeded the recommended level of $\geq 6$.

\section{Mechanical thresholds}

A Wagner algometer (FPX 25; Wagner Instruments, Greenwich, CT, USA) with a modified tip ${ }^{45}$ was used in this study for the purpose of mechanical threshold measurement. Thresholds were determined at distal radius, distal tibia, and surgical wound (abdomen) with the dog in lateral recumbency. For the radius, the algometer was placed over a bony surface at the distal end on the dorsal aspect, with the leg held extended. The tibia was tested on the distal laterodorsal surface where the bone could be palpated through the skin, with the leg held extended. The abdomen was tested at midpoint, $2 \mathrm{~cm}$ lateral to the midline incision on both sides. The radius was tested first, then the tibia, and lastly the abdomen. A response to the application of the probe was taken to be either a flinch, withdrawal of limb, or vocalization. Thresholds were determined in triplicate and the average was taken for each time point. The thresholds were measured before surgery with baseline at 0 hour and then after extubation at 1, 2, 4, 6, 8, 12, 18, 24, 30, 36, 42, 48, 60, and 72 hours. During threshold determination, the operator did not look at the reading of the algometer as he applied consistent force. The operator concentrated on the dogs' response and immediately stopped when the dogs exhibited the predefined response. The mechanical thresholds were cross-checked by another observer who recorded the algometer readings and dogs' responses. Both observers carried out the same tasks and were blinded to the treatments throughout this study. Furthermore, the dogs used in this study were well familiarized with the researchers, therefore did not require any restraining even at the time of palpation at wound. Thus, the researchers were well aware with the normal behavior of these dogs; therefore, any deviation from the normal behavior could easily be distinguished.

\section{Statistical analysis}

Statistical analysis was performed using the SPSS software package, version 20 (IBM SPSS Statistics 20). Prior to the analysis, data were checked for their conformance to the normal distribution using Kolmogorov-Smirnov normality test. Differences between the two groups in body weight, total surgery time, total anesthesia time, extubation time, and standing time were compared using Independent $t$-test. Differences between the treatment means were compared using Mann-Whitney $U$ test for nonparametric data. Differences within treatment across time points were compared with 
Wilcoxon signed-rank test for nonparametric data. Results were considered significant at $P<0.05$.

\section{Results}

There was no difference in the mean body weight, total anesthesia, surgery time, and time from extubation to sternal recumbency between KLT and T groups (Table 1). There was no difference in the ETiso concentration during anesthesia in both KLT and T groups (Table 2). One dog each in KLT and T groups moved during pulling pedicle and uterine body, where the ETiso was $1.4 \%$, and the isoflurane concentration was increased momentarily to $2 \%$ and $2.3 \%$, respectively. End tidal carbon dioxide concentration was significantly higher in KLT than in T group; as reflected by the lower respiratory rates in KLT compared to higher respiratory rates in $\mathrm{T}$ group throughout the surgery (Table 2). None of the dogs required rescue analgesia at any time up to 72 hours after surgery in both KLT and T groups.

\section{Intraoperative blood pressure, heart rate, and body temperature}

Blood pressure increased with skin incision and continued to be elevated throughout the surgery in the T group. In the KLT group, blood pressure was only elevated significantly during manipulation of the pedicles and uterine body (Table 3 ). Blood pressure in the $\mathrm{T}$ group was higher $(P=0.0001)$ than in KLT group throughout the surgery. Heart rate tended to increase with surgery in both the groups, but statistical difference from baseline was detected only during pulling of first and second pedicles in the $\mathrm{T}$ group. Body temperature did not differ significantly between the two treatments (Table 3 ).

\section{Postoperative sedation}

Sedation score was not different between the two treatment groups. All the animals in T group were alert and able to stand at 1 hour after extubation. In the KLT group, one dog was not able to stand at 1 hour and one dog at 2 hours after extubation, although they were alert and able to maintain sternal recumbency.

\section{Glasgow pain score}

At each time point, CMPS-SF scores between the groups were not different (Table 4). However, the CMPS-SF scores were statistically higher than baseline at 1,2,4,6, and 12 hours in the T group. In the KLT group, the CMPS-SF scores were elevated at 1 hour only. None of the dogs recorded CMPS-SF scores higher than 6 ; thus, rescue analgesia was not required throughout the study.

Table I Mean body weight, total surgery time, total anesthesia time, time to extubation, end tidal Iso at the time of extubation, sternal recumbency, and standing of dogs with KLT combination and T alone

\begin{tabular}{|c|c|c|c|}
\hline Parameter & KLT & $\mathbf{T}$ & P-value \\
\hline Body weight $(\mathrm{kg})$ & $16.40 \pm 2.20$ & $14.40 \pm 3.20$ & 0.24 \\
\hline Total surgery time (min) & $37.0 \pm 7.50$ & $33.0 \pm 5.20$ & 0.39 \\
\hline Total anesthesia time (min) & $88.0 \pm 19.20$ & $75.0 \pm 6.60$ & 0.16 \\
\hline Time from cessation of isoflurane to extubation ( $\mathrm{min}$ ) & $24.0 \pm 12.70$ & $10.0 \pm 6.20$ & 0.03 \\
\hline ETIso at the time of extubation (\%) & $0.27 \pm 0.03$ & $0.52 \pm 0.20$ & 0.02 \\
\hline Time from extubation to sternal recumbency (min) & $24.0 \pm 12.50$ & $13.0 \pm 11.90$ & 0.13 \\
\hline Time from extubation to standing (min) & $61.0 \pm 24.60$ & $30.0 \pm 18.10$ & 0.03 \\
\hline
\end{tabular}

Note: Data presented as mean \pm SD.

Abbreviations: ETIso, end-tidal isoflurane concentration; KLT, ketamine, lidocaine, and tramadol; T, tramadol.

Table 2 Median values (range) for ETiso concentration, respiration rate, and ETCO during surgical manipulations in both $\mathrm{KLT}$ and T groups

\begin{tabular}{|c|c|c|c|c|c|c|}
\hline \multirow[t]{2}{*}{ Event during surgery } & \multicolumn{2}{|c|}{ ETiso concentration (\%) } & \multicolumn{2}{|c|}{$\begin{array}{l}\text { Respiration rate } \\
\text { (breaths/min) }\end{array}$} & \multicolumn{2}{|c|}{$\mathrm{ETCO}_{2}$ concentration (\%) } \\
\hline & KLT & $\mathbf{T}$ & KLT & $\mathbf{T}$ & KLT & $\mathbf{T}$ \\
\hline Skin prep (baseline) & I.3 (I.I-I.5) & $\mathrm{I} .4(\mathrm{I} .4-\mathrm{I} .6)$ & $9(5-12)$ & $16(9-20)^{*}$ & $52(44-57)$ & $43(29-46)^{*}$ \\
\hline Skin incision & $\mathrm{I} .4(1.3-1.5)$ & $\mathrm{I} .4(\mathrm{I} .4-\mathrm{I} .6)$ & $7(5-13)$ & $17(16-19)^{*}$ & $57(48-64)$ & $40(22-48)^{*}$ \\
\hline First pedicle & $1.4(1.3-1.5)$ & $\mathrm{I} .4(\mathrm{I} .2-\mathrm{I} .5)$ & $11(6-18)$ & $17(16-25)^{*}$ & $56(49-66)$ & $37(32-45)^{*}$ \\
\hline Second pedicle & $1.4(1.4-1.5)$ & $1.4(1.2-1.8)$ & $10(6-17)$ & $16(15-20)^{*}$ & $57(49-76)$ & $40(32-45)^{*}$ \\
\hline Uterine body & $\mathrm{I} .4(\mathrm{I} .4-\mathrm{I} .5)$ & $\mathrm{I} .4(\mathrm{I} .2-2.0)$ & $10(4-17)$ & $18(16-30)^{*}$ & $58(54-73)$ & $40(35-45)^{*}$ \\
\hline Linea alba & $1.4(1.4-2.0)$ & $1.4(1.2-2.2)$ & $8(4-10)$ & $16(16-19)^{*}$ & $56(52-84)$ & $38(33-45)^{*}$ \\
\hline Subcutaneous & $1.4(1.4-1.7)$ & $1.3(1.2-2.3)$ & $8(6-11)$ & $17(14-22)^{*}$ & $55(37-60)$ & $38(30-43)^{*}$ \\
\hline Skin closure & $\mathrm{I} .4(\mathrm{I} .4-\mathrm{I} .7)$ & $1.4(1.3-2.2)$ & $9(6-11)$ & $18(|5-2|)^{*}$ & $55(37-60)$ & $38(30-43)^{*}$ \\
\hline
\end{tabular}

Notes: *Significantly different from KLT at corresponding time points (Mann-Whitney $U$ test $P<0.05$ ).

Abbreviations: KLT, ketamine, lidocaine, and tramadol; T, tramadol. 
Table 3 Median values (range) for intraoperative heart rate, mean blood pressure, and body temperature during surgical manipulations in both KLT and T groups

\begin{tabular}{|c|c|c|c|c|c|c|}
\hline \multirow{2}{*}{$\begin{array}{l}\text { Event during } \\
\text { surgery }\end{array}$} & \multicolumn{2}{|c|}{ Heart rate (beats/min) } & \multicolumn{2}{|c|}{ Mean blood pressure $(\mathrm{mm} \mathrm{Hg})$} & \multicolumn{2}{|c|}{ Body temperature $\left({ }^{\circ} \mathrm{C}\right)$} \\
\hline & KLT & $\mathbf{T}$ & KLT & $\mathbf{T}$ & KLT & $\mathbf{T}$ \\
\hline Skin prep (baseline) & $92(80-112)$ & $96(80-120)$ & $58(46-72)$ & $62(55-94)$ & $37.5(36.2-37.6)$ & $37.4(36.7-38.3)$ \\
\hline Skin incision & $102(73-119)$ & I07 (84-I I0) & $62(52-68)$ & $79(66-108)^{*, \#}$ & $37.3(36.4-37.5)$ & $37.1(36.6-38.0)$ \\
\hline First pedicle & $106(80-115)$ & $121(112-130)^{\#}$ & $95(66-110)^{\#}$ & $112(79-116)^{* \#}$ & $37.1(36.7-37.3)$ & $36.8(36.2-37.6)$ \\
\hline Second pedicle & $117(84-140)$ & $120(109-136)^{\#}$ & $99(64-122)^{\#}$ & $111(72-116)^{*, \#}$ & $36.9(36.4-37.3)$ & $36.6(36.0-37.6)$ \\
\hline Uterine body & $119(84-131)$ & $116(99-140)$ & $90(63-120)^{\#}$ & $109(78-117)^{*, \#}$ & $36.8(36.4-37.2)$ & $36.6(35.8-37.6)$ \\
\hline Linea alba & II (84-137) & $119(90-180)$ & $63(58-94)$ & $102(76-117)^{*, \#}$ & $36.7(35.9-37.2)$ & $36.5(35.7-37.5)$ \\
\hline Subcutaneous & $113(80-122)$ & $113(93-130)$ & $63(55-92)$ & $103(7 \mid-121)^{*, \#}$ & $36.6(35.6-37.2)$ & $36.4(35.5-37.5)$ \\
\hline Skin closure & $113(80-120)$ & $113(98-129)$ & $60(52-92)$ & $100(72-117)^{*, \#}$ & $36.5(35.5-37.2)$ & $36.3(35.5-37.4)$ \\
\hline
\end{tabular}

Notes: *Significantly different from KLT at corresponding time points (Mann-Whitney $U$ test $P<0.05$ ). ${ }^{*}$ Significantly different from values at skin preparation within group (Wilcoxon signed-rank test $P<0.05$ ).

Abbreviations: KLT, ketamine, lidocaine, and tramadol; T, tramadol.

Table 4 Median score (range) for Glasgow composite pain score

\begin{tabular}{|c|c|c|}
\hline Time (hours) & KLT & $\mathbf{T}$ \\
\hline 0 & $0(0-0)$ & $0(0-0)$ \\
\hline I & I $(I-3)^{\#}$ & $I(I-5)^{\#}$ \\
\hline 2 & $I(I-3)$ & $2(I-3)^{\#}$ \\
\hline 4 & $I(0-I)$ & $I(I-2)^{\#}$ \\
\hline 6 & I (0-2) & I $(0-2)^{\#}$ \\
\hline 8 & I (0-2) & I (0-2) \\
\hline 12 & I (0-2) & $I(0-1)^{\#}$ \\
\hline 18 & $0(0-2)$ & $0(0-1)$ \\
\hline 24 & $0(0-1)$ & $0(0-1)$ \\
\hline 30 & $0(0-0)$ & $0(0-0)$ \\
\hline 36 & $0(0-0)$ & $0(0-0)$ \\
\hline 42 & $0(0-0)$ & $0(0-0)$ \\
\hline 48 & $0(0-0)$ & $0(0-0)$ \\
\hline 60 & $0(0-0)$ & $0(0-0)$ \\
\hline 72 & $0(0-0)$ & $0(0-0)$ \\
\hline
\end{tabular}

Notes: No significant difference between treatments (Mann-Whitney $U$ test $P<0.05$ ). "Within group, significantly different from values at 0 hour (Wilcoxon Signed Rank test $P<0.05)$.

Abbreviations: KLT, ketamine, lidocaine, and tramadol; $T$, tramadol.

\section{Mechanical thresholds}

\section{Surgical wound at abdomen}

Following surgery, the mechanical thresholds decreased significantly compared to baseline throughout the 72 hours in the T group. In the KLT group, the thresholds were not different from baseline for up to 8 hours, and decreased significantly from 12 to 60 hours compared to baseline. Thresholds in group $\mathrm{T}$ tended to be lower than in KLT from 1 to 72 hours, with time significance detected at 8 hours postoperatively (Table 5).

\section{Distal tibia}

In both the groups, thresholds at 1 hour postoperatively were higher than baseline. Thereafter, the thresholds gradually decreased to values lower than baseline at time points between
24 and 72 hours in group T. In group KLT, thresholds lower than baseline values were significant only at 24,42 , and 60 hours postoperatively (Table 5). There was no statistical difference in postoperative mechanical thresholds between KLT and T groups at any time point; however, the mechanical thresholds tended to be lower in T group than in KLT group at $30(P=0.109), 36(P=0.173), 42(P=0.075), 48(P=0.150)$, and $60(P=0.150)$ hours (Table 5).

\section{Distal radius}

Mechanical thresholds at distal radius in both the groups increased higher than baseline in the first 4-6 hours after surgery and then reduced. The reduction was steeper in the $\mathrm{T}$ group; the thresholds became significantly lower than in KLT group at 24 and 36 hours and continued to decrease below their baseline values between 36 and 48 hours. In the KLT group, significantly lower values than baseline value were not detected at any time point (Table 5).

\section{Postoperative heart rate, respiration rate, and body temperature}

There was no treatment difference in the postoperative heart rate, respiratory rate, and body temperature of the dogs.

\section{Discussion}

In this study, the addition of ketamine-lidocaine infusion to pre-emptive tramadol provided better intraoperative and postoperative analgesia in dogs undergoing ovariohysterectomy. The addition of ketamine-lidocaine infusion reduced the increment of intraoperative blood pressure to a greater extent compared to tramadol alone. Postoperatively, the addition of ketamine-lidocaine reduced the decrement of mechanical thresholds at the site of surgery (primary hyperalgesia) for 
Table 5 Median values (range) for postoperative mechanical thresholds (Newton) at the abdomen, distal tibia, and distal radius of dogs treated with KLT and T

\begin{tabular}{|c|c|c|c|c|c|c|}
\hline \multirow{2}{*}{$\begin{array}{l}\text { Time point } \\
\text { (hour) }\end{array}$} & \multicolumn{2}{|l|}{ Abdomen } & \multicolumn{2}{|l|}{ Distal tibia } & \multicolumn{2}{|l|}{ Distal radius } \\
\hline & KLT & $\mathbf{T}$ & KLT & $\mathbf{T}$ & KLT & $\mathbf{T}$ \\
\hline Baseline & $5.0(3.5-5.9)$ & $4.4(4.3-5.0)$ & $8.0(6.6-16.0)$ & $8.0(6.9-8.4)$ & $8.0(6.4-12.2)$ & $7.4(6.4-10.5)$ \\
\hline 1 & $3.2(0.7-13.9)$ & $1.9(1.1-3.7)^{\#}$ & II.7 (7.8-18.0)\# & II $.5(7.5-16.7)^{\#}$ & | $3.3(8.7-\mid 8.0)^{\#}$ & $11.2(10.1-18.0)^{\#}$ \\
\hline 2 & $2.4(0.6-11.1)$ & $1.5(1.2-2.7)^{\#}$ & $8.5(5.3-18.0)$ & $10.8(5.3-17.3)$ & I2.9 (7.8-18.0) & II.6 (7.0-18.0) \\
\hline 4 & $2.2(0.8-7.9)$ & $\mathrm{I} .5(0.7-2.5)^{\#}$ & $8.8(7.3-16.5)$ & II.0 (5.0-15.5) & $9.5(7.5-18.0)$ & II $.0(7.3-14.0)^{\#}$ \\
\hline 6 & $1.9(1.0-8.0)$ & $1.4(1.1-2.9)^{\#}$ & $9.2(5.5-15.0)$ & $7.7(6.7-15.0)$ & $10.6(7.1-13.3)^{\#}$ & $9.0(6.4-13.3)$ \\
\hline 8 & $2.0(1.6-6.7)$ & $1.3(1.0-2.0)^{*, \#}$ & $8.9(5.5-18.0)$ & $8.9(5.8-9.6)$ & $9.9(5.3-17.8)$ & $8.1(6.1-12.3)$ \\
\hline 12 & $1.9(0.8-3.8)^{\#}$ & $\mathrm{I} .0(0.8-\mid .5)^{\#}$ & $8.0(6.0-16.3)$ & $7.1(5.2-9.0)$ & $8.6(6.7-16.0)$ & $7.0(6.0-8.1)$ \\
\hline 18 & I.8 $(0.6-2.4)^{\#}$ & I.0 (0.8-I.5) & $6.9(5.8-1 \mid .2)$ & $6.7(4.6-9.6)$ & $8.1(6.3-12.1)$ & $6.4(5.6-9.2)$ \\
\hline 24 & $2.1(0.8-2.5)^{\#}$ & I.I (0.9-I.7) & $6.7(4.4-7.4)^{\#}$ & $6.4(4.8-9.3)^{\#}$ & $8.6(5.4-9.6)$ & $6.4(5.4-7.2)^{*}$ \\
\hline 30 & $1.6(0.5-2.9)^{\#}$ & $0.9(0.7-1.4)^{\#}$ & $7.4(5.0-9.4)$ & $5.6(3.8-8.0)^{\#}$ & $7.3(5.8-9.5)$ & $5.8(4.4-7.5)$ \\
\hline 36 & $2.0(0.2-3.1)^{\#}$ & $1.0(0.7-1.7)^{\#}$ & $6.7(4.9-7.5)$ & $5.4(3.5-6.6)^{\#}$ & $7.5(6.2-9.5)$ & $5.7(5.5-7.2)^{*, \#}$ \\
\hline 42 & $2.1(0.2-3.2)^{\#}$ & I.I $(0.6-1.8)^{\#}$ & $6.2(5.9-7.2)^{\#}$ & $5.8(3.8-6.5)^{\#}$ & $7.8(6.3-9.3)$ & $6.2(4.9-7.3)^{\#}$ \\
\hline 48 & $1.9(0.2-3.2)^{\#}$ & I.3 $(0.7-2.8)^{\#}$ & $7.1(5.2-7.6)$ & $5.7(4.4-7.9)^{\#}$ & $6.9(6.9-8.2)$ & $6.1(5.5-7.4)^{\#}$ \\
\hline 60 & $1.9(0.5-3.1)^{\#}$ & I.0 $(0.7-3.8)^{\#}$ & $6.6(5.3-9.1)^{\#}$ & $5.4(3.6-7.6)^{\#}$ & $7.0(5.4-9.4)$ & $6.4(5.6-7.2)$ \\
\hline 72 & 2.I (0.5-6.8) & I.I $(0.7-4.4)^{\#}$ & $7.0(5.4-7.8)$ & $6.0(4.2-8.6)^{\#}$ & $7.7(6.6-9.4)$ & $6.7(4.6-7.3)$ \\
\hline
\end{tabular}

Notes: *Significantly different from KLT at corresponding time point (Mann-Whitney $U$ test $P<0.05$ ). "Significantly different from baseline values within group (Wilcoxon signed-rank test $P<0.05)$.

Abbreviations: KLT, ketamine, lidocaine, and tramadol; T, tramadol.

the first 8 hours, and prevented the decrement of mechanical thresholds throughout the study at the distal tibia and radius (secondary hyperalgesia).

Intraoperative mean blood pressure and respiration were higher in T group compared to KLT group. In the KLT group, mean blood pressures were elevated from baseline only during stimulation of the first pedicle, second pedicle, and uterine body, while the pressures were elevated throughout the whole surgery in the $\mathrm{T}$ group. Likewise, the respiratory rates were higher in T group throughout the surgery compared to KLT group. Significant increment in the heart rates during stimulation of pedicles was observed in T group, but not in KLT group. Traction of mesovarium during ovariectomy is known to produce the strongest noxious stimulation, therefore resulting in the highest change in blood pressures, heart rates, and respiratory rates due to stimulation of sympathetic nervous system. ${ }^{46-49}$ Thus, in this study, changes in respiration, heart rates, and blood pressures in the tramadol group indicate that, addition of ketamine-lidocaine obtunded the sympathetic response to surgical stimulation more than tramadol alone.

In this study, the median ETiso throughout surgery in both groups was found to be around $1.4 \%$, and was not different between groups. However, the respiratory rates were lower in KLT group, resulting in higher end-tidal carbon tidal concentration compared to that in $\mathrm{T}$ group. Ketamine and lidocaine have been reported to reduce the ETiso to maintain anesthesia in dogs. ${ }^{50,51}$ Thus, the addition of ketamine-lidocaine infusion in this study likely has increased the depth of anesthesia and contributed to the respiratory depression.

Surgery contributes to postoperative pain hypersensitivity, and this can be objectively demonstrated as decrement in mechanical thresholds. ${ }^{24,25,26}$ Decrement of thresholds at the secondary sites distant from surgery reflects development of central sensitization. Therefore, attenuation of these changes would suggest attenuation of central sensitization. In this study, mechanical thresholds at the abdomen (primary site) decreased postoperatively for a shorter duration in KLT group, compared to the entire 72 hours in T group, suggesting more adequate postoperative analgesia in the immediate postoperative period (up to 8 hours) in KLT group. Similar trends were demonstrated at the distal tibia (secondary site). At the distal radius, KLT successfully suppressed decrement of thresholds throughout the 72 hours of study. These findings strongly suggest the benefits of ketamine-lidocaine infusion, even when administered for 2 hours, to prevent central hypersensitivity.

The more prolonged decrement of thresholds at the distal tibia compared to that at the distal radius in this study concurred with the findings reported by Lascelles et al. ${ }^{24}$ This phenomenon may reflect greater changes to the central synaptic plasticity, and closer proximity of the spinal cord segments supplying the distal tibia and the abdominal muscles, compared to distal radius. Consequently, the addition of ketamine-lidocaine infusion could suppress development 
of allodynia at the distal radius better than distal tibia, as shown in this study.

Combination of subjective as well as objective tools for assessing the analgesic efficacy of drugs in the postoperative period may give more optimum results compared to using each tool alone. The CMPS-SF has been validated and reported to be able to distinguish pain of different severities. ${ }^{52}$ Using this pain scale, differences in postoperative pain between KLT and T groups have been shown in this study. Pain scores significantly increased from baseline only at the first hour in KLT, compared to 12 hours in the T group. The quicker return to baseline pain score suggests better postoperative analgesia in the KLT group. Furthermore, the highest pain score recorded was score 3 in KLT group versus score 5 in $\mathrm{T}$ group. The recommended score for analgesic intervention is 6 out of a maximum of 24 for this pain scale ${ }^{53,54}$ thus, none of the dogs in this study required rescue analgesia.

Level of consciousness in response to sedatives may alter the pain assessment, resulting in masking of the actual pain scores. Therefore, no other sedative was used in this study apart from the tested drugs. Most of the dogs in the T group were alert and able to walk normally at 1 hour postextubation. One dog in the KLT group was unable to stand at 1 hour and another $\operatorname{dog}$ at 2 hours postextubation; however, they were alert and able to maintain sternal recumbency.

Pre-emptive analgesia has been defined as "an antinociceptive treatment that prevents establishment of altered central processing of afferent input from injuries". ${ }^{55}$ Practically, pre-emptive analgesia means the injection of analgesic agent before the start of surgical stimulus with the aim of preventing or reducing subsequent pain. ${ }^{56}$ Injection of a drug simply before surgery without considering its pharmacology is not considered as true "pre-emptive analgesia". Multimodal analgesia is the term given to the technique in which different analgesics with various modes of action are mixed with the aim of acting on different pathways and neurotransmitters involved in nociception and hyperalgesia. ${ }^{23}$ Postoperative pain is the result of four steps of nociception, which are transduction, transmission, perception, and modulation. ${ }^{57}$ The rationale of multimodal analgesia, therefore, should be to target these steps in the nociceptive pathways, in order to prevent development of central sensitization. In this context, we combined ketamine-lidocaine on the top of tramadol.

Systemic lidocaine produces analgesia as a result of its multifactorial interactions with sodium channels and direct or indirect interaction with various receptors and nociceptive transmission pathways. Besides its main action on the sodium channels, it decreases glutamate release from the cerebrocortical nerve terminals and increases extracellular glycine concentration resulting in enhanced activity at the inhibitory glycinergic synapses by inhibition of GlyT1-mediated glycine reuptake at the supraspinal level. It has been reported to reduce neurokinins and the production of thromboxane A2, and it releases endogenous opioids. ${ }^{17}$ Ketamine, on the other hand, acts on the calcium channels at the NMDA receptors, resulting in the attenuation of the exaggerated nociceptive action potentials, thus diminishing the pain sensation. It blocks $\mathrm{Na}^{+}$channels in the peripheral and central nervous systems, and interacts with monoaminergic and voltagesensitive $\mathrm{Ca}^{+2}$ channels. ${ }^{16,58}$ It has been reported to inhibit the glial cell activation and reduce the proinflammatory cytokines interleukin- $1 \beta$, interleukin- 6 , and tumor necrosis factor- $\alpha .{ }^{59}$ Tramadol produces analgesia by inhibiting noradrenaline reuptake and through the increased release and inhibition of serotonin reuptake. ${ }^{19,20}$ Thus, tramadol activates both systems involved in the inhibition of pain: the opioid and the descending monoaminergic system. It has low affinity for the $\mu, \delta, \kappa$ opioid receptors and weaker affinity for the kappa subtype.

An increase in intracellular $\mathrm{Ca}^{2+}$ in response to $\mathrm{Mg}^{2+}$ removal is the key trigger for initiating central sensitization. Normally, magnesium $\left(\mathrm{Mg}^{2+}\right)$ ion keeps the receptor pore closed and prevents calcium $\left(\mathrm{Ca}^{2+}\right)$ influx. Continuous release of glutmate, substance $\mathrm{P}$, and calcitonin gene-related peptide results in sufficient membrane depolarization forcing the $\mathrm{Mg}^{2+}$ to allow $\mathrm{Ca}^{2+}$ influx into the neuron, activating the intracellular pathways boosting the synaptic efficacy. Calcitonin gene-related peptide also enhances the release of brain-derived neurotrophic factor (BDNF) from nociceptor neurons. BDNF binds to trkB receptor and enhances NMDAR-mediated C-fiber-evoked responses, and causes activation of several signaling pathways in spinothalamic track neurons, including extracellular signal-regulated kinase and protein kinase $\mathrm{C}$. Extracellular signal-regulated kinase is also activated by a serotoninergic (5-HT) descending input involving the ionotropic $5-\mathrm{HT}_{3}$ receptor and possibly the $5-\mathrm{HT}_{7} \mathrm{GS}$-coupled receptor. Activation of protein kinase $\mathrm{C}$ contributes to hyperexcitability and maintenance of central sensitization by increasing the probability of NMDA receptor opening through removing the $\mathrm{Mg}^{2+}$ block on the one hand and decreasing inhibitory transmission by reducing gamma-aminobutyric acid and glycine tonic inhibition as well as the descending inhibition driven from the periaqueductal gray (PAG) on the other hand. This leaves the dorsal horn neurons more prone to activation by excitatory inputs 
including non-nociceptive A-fibers. Central sensitization is induced within seconds of intense and repeated nociceptive stimuli and lasts for tens of minutes to several hours in the absence of further stimuli. ${ }^{1}$

Spinal LTP has been reported to play a role in central sensitization. Spinal LTP has been proposed to be a cellular mechanism of pain amplification in acute and chronic pain states that develop from an initial painful event. The induction of nearly all forms of spinal LTP is blocked by application of NMDA receptor antagonist. ${ }^{4}$

Ketamine at $10 \mathrm{mg} / \mathrm{kg}$ intraperitoneally alleviated the pain behavior in rats through inhibition of upregulation of phosphorylated and total NMDA receptors at the spinal level ${ }^{60}$ In clinical cases of complex regional pain syndrome, addition of ketamine $0.5 \mathrm{mg} / \mathrm{kg}$ to the sympathetic blocks provided significant relief in allodynia. ${ }^{61}$ In a behavioral study, chronic ketamine prevented BDNF-induced mechanical hyperalgesia in rats. ${ }^{62}$ Likewise, systemic lidocaine at $2 \mathrm{mg} / \mathrm{kg}$ bolus significantly suppressed development of acute mechanical hyperalgesia during tonic pressure. ${ }^{63}$ Systemic lidocaine decreased pain and morphine requirement (103.1 \pm 72.0 versus $159.0 \pm 73.3 \mathrm{mg}$ ) after major abdominal surgery. ${ }^{64}$ In a clinical study, pre-emptive lidocaine improved immediate postoperative pain after transabdominal hysterectomy. ${ }^{65}$

Taking together all the lines of evidences, mode of action of ketamine, lidocaine, tramadol, and the findings of this study, it can be concluded that addition of ketamine-lidocaine to preoperative IV bolus of tramadol significantly attenuated the development of central sensitization likely by blocking the various pathways involved in postoperative pain; with subsequent decrease in postoperative pain and analgesic requirement during the 72 -hour study period in dogs.

Proper pain relief is one of the primary concerns in both human and veterinary medicine due to its close ties with postoperative standard of care and patient well-being. In this context, this study was conducted to evaluate the analgesic effects of ketamine-lidocaine infusion in addition to single intravenous dose of tramadol during and after ovariohysterectomy in a dog model. Drugs were administered before the start of surgery as pre-emptive multimodal analgesia. Algometry and short form of the Glasgow composite pain scale were used to measure postoperative pain up to 72 hours. The addition of ketamine-lidocaine infusion to single intravenous dose of tramadol significantly dampened intraoperative hemodynamic responses, reduced secondary hyperalgesia, and improved postoperative analgesia.

\section{Conclusion}

This study demonstrated that pre-emptive use of KLT obtunded intraoperative sympathetic responses better than tramadol alone. The KLT combination attenuated primary hyperalgesia better than tramadol in the immediate 8 hours postsurgery and helped to reduce secondary hyperalgesia during the 72-hour postoperative study period. Results of this study support the pre-emptive use of ketamine-lidocaine infusion in addition to tramadol for suppression of central sensitization to enhance postoperative pain relief. Mechanism of action of IV lidocaine and ketamine and the results of this study show that both the drugs have potential for attenuating central sensitization and are important candidates for the pre-emptive multimodal analgesia protocols for postoperative pain management. However, further research is necessary to evaluate IV lidocaine and ketamine on more surgical models adjudged to have higher pain intensity, such as orthopedics with the CRI for periods covering pre-, intra- and immediate postsurgical period until recovery.

\section{Acknowledgment}

The authors are very grateful to the Faculty of Veterinary Medicine, Universiti Putra Malaysia.

\section{Author contributions}

All authors made a significant contribution to study concept and design, acquisition of data, analysis and interpretation of data, drafting or revising the manuscript for important intellectual content, and approval of the final version to be published.

\section{Disclosure}

The authors report no conflicts of interest in this work.

\section{References}

1. Latremoliere A, Woolf CJ. Central sensitization: a generator of pain hypersensitivity by central neural plasticity. J Pain. 2009;10(9): 895-926.

2. Muir WW 3rd, Woolf CJ. Mechanisms of pain and their therapeutic implications. J Am Vet Med Assoc. 2001;219(10):1346-1356.

3. Li S, Cai J, Feng ZB, et al. BDNF contributes to spinal long-term potentiation and mechanical hypersensitivity via fyn-mediated phosphorylation of NMDA receptor GluN2B subunit at tyrosine 1472 in rats following spinal nerve ligation. Neurochem Res. 2017;11(10):017-2274.

4. Ruscheweyh R, Wilder-Smith O, Drdla R, Liu XG, Sandkuhler J. Longterm potentiation in spinal nociceptive pathways as a novel target for pain therapy. Mol Pain. 2011;7(20):1744-8069.

5. Drdla R, Sandkuhler J. Long-term potentiation at C-fibre synapses by low-level presynaptic activity in vivo. Mol Pain. 2008;4(18):1744-8069.

6. Ren K, Dubner R. Interactions between the immune and nervous systems in pain. Nat Med. 2010;16(11):1267-1276. 
7. Cummins TR. Setting up for the block: the mechanism underlying lidocaine's use-dependent inhibition of sodium channels. J Physiol. 2007;582(Pt 1):24.

8. Benrath J, Brechtel C, Stark J, Sandkuhler J. Low dose of S+ketamine prevents long-term potentiation in pain pathways under strong opioid analgesia in the rat spinal cord in vivo. Br J Anaesth. 2005;95(4):518-523.

9. Ikeda H, Stark J, Fischer H, et al. Synaptic amplifier of inflammatory pain in the spinal dorsal horn. Science. 2006;312(5780):1659-1662.

10. Liu XG, Sandkuhler J. Long-term potentiation of C-fiber-evoked potentials in the rat spinal dorsal horn is prevented by spinal N-methylD-aspartic acid receptor blockage. Neurosci Lett. 1995;191(1-2):43-46.

11. Woolf CJ, Thompson SW. The induction and maintenance of central sensitization is dependent on N-methyl-D-aspartic acid receptor activation; implications for the treatment of post-injury pain hypersensitivity states. Pain. 1991;44(3):293-299.

12. Babos MB, Grady B, Wisnoff W, McGhee C. Pathophysiology of pain. Dis Mon. 2013;59(10):330-358.

13. Gold MS, Gebhart GF. Nociceptor sensitization in pain pathogenesis. Nat Med. 2010;16(11):1248-1257.

14. Klein T, Magerl W, Nickel U, Hopf HC, Sandkuhler J, Treede RD. Effects of the NMDA-receptor antagonist ketamine on perceptual correlates of long-term potentiation within the nociceptive system. Neuropharmacology. 2007;52(2):655-661.

15. Daniel BC. BM. Pain After Surgery: What Health-Care Professionals Should Know. Fact Sheet No 2. The International Association for the Study of Pain. (2017).

16. Weinbroum AA. Non-opioid IV adjuvants in the perioperative period: pharmacological and clinical aspects of ketamine and gabapentinoids. Pharmacol Res. 2012;65(4):411-429.

17. Lauretti GR. Mechanisms of analgesia of intravenous lidocaine. Rev Bras Anestesiol. 2008;58(3):280-286.

18. Tanelian DL, MacIver MB. Analgesic concentrations of lidocaine suppress tonic A-delta and $\mathrm{C}$ fiber discharges produced by acute injury. Anesthesiology. 1991;74(5):934-936.

19. KuKanich B, Papich MG. Pharmacokinetics of tramadol and the metabolite O-desmethyltramadol in dogs. $J$ Vet Pharmacol Ther 2004;27(4):239-246.

20. McMillan CJ, Livingston A, Clark CR, et al. Pharmacokinetics of intravenous tramadol in dogs. Can J Vet Res. 2008;72(4):325-331.

21. Doherty T, Redua MA, Queiroz-Castro P, Egger C, Cox SK, Rohrbach BW. Effect of intravenous lidocaine and ketamine on the minimum alveolar concentration of isoflurane in goats. Vet Anaesth Analg 2007;34(2):125-131.

22. Woolf CJ, Salter MW. Neuronal plasticity: increasing the gain in pain Science. 2000;288(5472):1765-1769.

23. Kehlet H, Dahl JB. The value of "multimodal" or "balanced analgesia" in postoperative pain treatment. Anesth Analg. 1993;77(5):1048-1056

24. Lascelles BD, Cripps PJ, Jones A, Waterman AE. Post-operative central hypersensitivity and pain: the preemptive value of pethidine for ovariohysterectomy. Pain. 1997;73(3):461-471.

25. Lascelles BD, Cripps PJ, Jones A, Waterman-Pearson AE. Efficacy and kinetics of carprofen, administered preoperatively or postoperatively, for the prevention of pain in dogs undergoing ovariohysterectomy. Vet Surg. 1998;27(6):568-582.

26. Slingsby LS, Waterman-Pearson AE. The post-operative analgesic effects of ketamine after canine ovariohysterectomy-a comparison between pre- or post-operative administration. Res Vet Sci. 2000;69(2):147-152.

27. Lowenstein L, Zimmer EZ, Deutsch M, Paz Y, Yaniv D, Jakobi P. Preoperative analgesia with local lidocaine infiltration for abdominal hysterectomy pain management. Eur J Obstet Gynecol Reprod Biol. 2008;136(2):239-242.

28. Barczynski M, Konturek A, Herman RM. Superiority of preemptive analgesia with intraperitoneal instillation of bupivacaine before rather than after the creation of pneumoperitoneum for laparoscopic cholecystectomy: a randomized, double-blind, placebo-controlled study. Surg Endosc. 2006;20(7):1088-1093.
29. Zor ZF, Isik B, Cetiner S. Efficacy of preemptive lornoxicam on postoperative analgesia after surgical removal of mandibular third molars. Oral Surg Oral Med Oral Pathol Oral Radiol. 2014;117(1):27-31.

30. Reuben SS, Bhopatkar S, Maciolek H, Joshi W, Sklar J. The preemptive analgesic effect of rofecoxib after ambulatory arthroscopic knee surgery. Anesth Analg. 2002;94(1):55-59.

31. El Sonbaty MI, Abo el Dahab H, Mostafa A, Abo Shanab O. Preemptive peritonsillar ketamine infiltration: postoperative analgesic efficacy versus meperidine. Middle East J Anaesthesiol. 2011;21(1):43-51.

32. Kang H, Ha YC, Kim JY, Woo YC, Lee JS, Jang EC. Effectiveness of multimodal pain management after bipolar hemiarthroplasty for hip fracture: a randomized, controlled study. J Bone Joint Surg Am. 2013;95(4):291-296.

33. Gutierrez-Blanco E, Victoria-Mora JM, Ibancovichi-Camarillo JA, et al. Postoperative analgesic effects of either a constant rate infusion of fentanyl, lidocaine, ketamine, dexmedetomidine, or the combination lidocaine-ketamine-dexmedetomidine after ovariohysterectomy in dogs. Vet Anaesth Analg. 2015;42(3):309-318.

34. Kona-Boun JJ, Cuvelliez S, Troncy E. Evaluation of epidural administration of morphine or morphine and bupivacaine for postoperative analgesia after premedication with an opioid analgesic and orthopedic surgery in dogs. J Am Vet Med Assoc. 2006;229(7):1103-1112.

35. Kelly DJ, Ahmad M, Brull SJ. Preemptive analgesia I: physiological pathways and pharmacological modalities. Can J Anaesth. 2001;48(10):1000-1010.

36. Kajiume T, Sera Y, Nakanuno R, et al. Continuous intravenous infusion of ketamine and lidocaine as adjuvant analgesics in a 5-year-old patient with neuropathic cancer pain. J Palliat Med. 2012;15(6):719-722.

37. McCarthy GC, Megalla SA, Habib AS. Impact of intravenous lidocaine infusion on postoperative analgesia and recovery from surgery: a systematic review of randomized controlled trials. Drugs. 2010;70(9):1149-1163.

38. Laskowski K, Stirling A, McKay WP, Lim HJ. A systematic review of intravenous ketamine for postoperative analgesia. Can J Anaesth. 2011;58(10):911-923.

39. Guimaraes Alves IP, Montoro Nicacio G, Diniz MS, Alves Rocha TL, Prada Kanashiro G, Navarro Cassu R. Analgesic comparison of systemic lidocaine, morphine or lidocaine plus morphine infusion in dogs undergoing fracture repair. Acta Cir Bras. 2014;29(4):245-251.

40. Tsai TY, Chang SK, Chou PY, Yeh LS. Comparison of postoperative effects between lidocaine infusion, meloxicam, and their combination in dogs undergoing ovariohysterectomy. Vet Anaesth Analg. 2013;40(6):615-622.

41. Columbano N, Secci F, Careddu GM, Sotgiu G, Rossi G, Driessen B Effects of lidocaine constant rate infusion on sevoflurane requirement, autonomic responses, and postoperative analgesia in dogs undergoing ovariectomy under opioid-based balanced anesthesia. Vet J. 2012;193(2):448-455.

42. Kaka U, Saifullah B, Abubakar AA, et al. Serum concentration of ketamine and antinociceptive effects of ketamine and ketamine-lidocaine infusions in conscious dogs. BMC Vet Res. 2016;12(1):198.

43. Monteiro ER, Junior AR, Assis HM, Campagnol D, Quitzan JG. Comparative study on the sedative effects of morphine, methadone, butorphanol or tramadol, in combination with acepromazine, in dogs. Vet Anaesth Analg. 2009;36(1):25-33.

44. Savvas I, Papazoglou LG, Kazakos G, Anagnostou T, Tsioli V, Raptopoulos D. Incisional block with bupivacaine for analgesia after celiotomy in dogs. J Am Anim Hosp Assoc. 2008;44(2):60-66.

45. Kaka U, Chen HC, Goh YM, Abubakar AA, Fakurazi S, Ebrahimi M. Validation of a modified algometer to measure mechanical nociceptive thresholds in awake dogs. Biomed Res Int. 2015;(10):375421.

46. Boscan P, Monnet E, Mama K, et al. A dog model to study ovary, ovarian ligament and visceral pain. Vet Anaesth Analg. 2011;38(3):260-266.

47. Firth AM, Haldane SL. Development of a scale to evaluate postoperative pain in dogs. J Am Vet Med Assoc. 1999;214(5):651-659.

48. Bonica JJ. Response to pain and injury. In: Lumb and Jones'Veterinary Anesthesia and Analgesia. 4th ed. Ames: Blackwell Publishing; 2007:33-57. 
49. Burton D, Nicholson, G, Hall, GM Endocrine and metabolic response to surgery. Cont Educ Anaesth Crit. Care Pain 2004;4(5): 144-147.

50. Muir WW 3rd, Wiese AJ, March PA. Effects of morphine, lidocaine, ketamine, and morphine-lidocaine-ketamine drug combination on minimum alveolar concentration in dogs anesthetized with isoflurane. Am J Vet Res. 2003;64(9):1155-1160.

51. Solano AM, Pypendop BH, Boscan PL, Ilkiw JE. Effect of intravenous administration of ketamine on the minimum alveolar concentration of isoflurane in anesthetized dogs. Am J Vet Res. 2006;67(1):21-25.

52. Murrell JC, Psatha EP, Scott EM, Reid J, Hellebrekers LJ. Application of a modified form of the Glasgow pain scale in a veterinary teaching centre in the Netherlands. Vet Rec. 2008;162(13):403-408.

53. Holton., Reid J, Scott EM, Pawson P, Nolan A. Development of a behaviour-based scale to measure acute pain in dogs. Vet Rec. 2001;148(17):525-531.

54. Reid J, Nolan A, Hughes J, Lascelles D, Pawson P, Scott E. Development of the short-form Glasgow Composite Measure Pain Scale (CMPS$\mathrm{SF})$ and derivation of an analgesic intervention score. Animal Welfare. 2007;16 (Suppl 1):97-104.

55. Kelly DJ, Ahmad M, Brull SJ. Preemptive analgesia II: recent advances and current trends. Can J Anaesth. 2001;48(11):1091-1101.

56. Grape S, Tramer MR. Do we need preemptive analgesia for the treatment of postoperative pain? Best Pract Res Clin Anaesthesiol. 2007;21(1):51-63.

57. Loveridge R, Patel S. Systemic non-opioid adjuvant analgesics: their role in acute postoperative pain in adults. Trends Anaesth Crit Care. 2014;4(1):10-18.
58. Hirota K, Lambert DG. Ketamine: its mechanism(s) of action and unusual clinical uses. Br J Anaesth. 1996;77(4):441-444.

59. Wu Y, Li W, Zhou C, et al. Ketamine inhibits lipopolysaccharide-induced astrocytes activation by suppressing TLR4/NF-kB pathway. Cell Physiol Biochem. 2012;30(3):609-617.

60. Shen Y, Xu L, Liu M, Lei Y, Gu X, Ma Z. The effects of an intraperitoneal single low dose of ketamine in attenuating the postoperative skin/ muscle incision and retraction-induced pain related to the inhibition of N-methyl-D-aspartate receptors in the spinal cord. Neurosci Lett. 2016;616:211-217.

61. Sunder RA, Toshniwal G, Dureja GP. Ketamine as an adjuvant in sympathetic blocks for management of central sensitization following peripheral nerve injury. J Brachial Plex Peripher Nerve Inj. 2008;3(22):1749-7221.

62. Marcos JL, Galleguillos D, Pelissier T, et al. Role of the spinal TrkBNMDA receptor link in the BDNF-induced long-lasting mechanical hyperalgesia in the rat: a behavioural study. Eur J Pain. 2017;21(10): 1688-1696.

63. Koppert W, Zeck S, Sittl R, Likar R, Knoll R, Schmelz M. Low-dose lidocaine suppresses experimentally induced hyperalgesia in humans. Anesthesiology. 1998;89(6):1345-1353.

64. Koppert W, Weigand M, Neumann F, et al. Perioperative intravenous lidocaine has preventive effects on postoperative pain and morphine consumption after major abdominal surgery. Anesth Analg. 2004;98(4): $1050-1055$.

65. Yardeni IZ, Beilin B, Mayburd E, Levinson Y, Bessler H. The effect of perioperative intravenous lidocaine on postoperative pain and immune function. Anesth Analg. 2009;109(5):1464-1469.
Journal of Pain Research

\section{Publish your work in this journal}

The Journal of Pain Research is an international, peer reviewed, open access, online journal that welcomes laboratory and clinical findings in the fields of pain research and the prevention and management of pain. Original research, reviews, symposium reports, hypothesis formation and commentaries are all considered for publication.

\section{Dovepress}

The manuscript management system is completely online and includes a very quick and fair peer-review system, which is all easy to use. Visit http://www.dovepress.com/testimonials.php to read real quotes from published authors. 